\title{
Multiple regression analysis of ground level ozone and its precursor pollutants in coastal mega city of Mumbai, India
}

\begin{abstract}
The concentration of ground level ozone is reported to be increasing in most of the developing and developed nations. High ozone concentrations have been reported to be responsible for premature deaths, damages to flora and fauna, loss in crop yields and several other environmental impacts. Thus it is important find the causes which lead to ozone formation. But in most of the cases it is noticed that the research is directed towards only monitoring and reporting the trends of ground level ozone and its precursor pollutants. A considerable number of studies have reported that ozone formation is a regional phenomenon and needs to be addressed locally as well as globally. Considering the same; the present study aims to find out the factors responsible for the formation of ground level ozone in one of the megacities India (Mumbai).
\end{abstract}

\section{A new approach}

In the present study the time taken for formation of ozone after emission of precursors is taken in to consideration. This was accomplished by offsetting the ozone values by one hour and adjusting them with the precursor pollutants. The parameters selected for analysis were based on the available literature. Step-wise regression analysis of pollutants in logarithmic form was carried out in order to understand factors influencing ozone formation. In order to understand ozone formation in detail, the study was carried for individual seasons experienced in the unique tropical climate as well for the entire data set to corroborate the findings. The study concludes with highlighting most important factors which influence ground level ozone formation. The present study will help to understand the factors which are critical for formation of ground level ozone and how they change with respect to change in seasons. This is expected to help policy planers in their decision making.

Keywords: regression analysis of ozone, ground level ozone, air quality of Mumbai, ozone pollution in coastal megacities, ozone formation in tropical cities, formation of ground level ozone
Volume 2 Issue 6 - 2017

\author{
Sagar A Marathe,' Shankar Murthy,' Nachiket \\ Gosawi,' Mihir Herlekar² \\ 'National Institute of Industrial Engineering, India \\ ${ }^{2}$ University of Mumbai, India
}

Correspondence: Sagar A Marathe, Fellow, National Institute of Industrial Engineering, 400087 Mumbai, India, Tel 91-976-940139-6, Email sagaralwaysthere@gmail.com

Received: April 28, 2017| Published: August 29, 2017

\section{Introduction}

The problem of ground level ozone is familiar to almost all the nations in the world. The levels of ozone are reported to be frequently exceeding the prescribed guidelines and hence have found their way into news papers. The effects of ground level ozone pollution have been studied in detail by various researchers world-wide. ${ }^{1-7}$ These researchers have reported that concentration of ozone is increasing in most parts of the world. Their studies conclude that the rate of pollution is so high that even the background levels of ozone have also risen. Even in developing nations like India the rising concentrations of ozone are being reported from various parts of the country. The study conducted by Naja and Lal (1996) reports that the ozone concentrations are rising at a rate of $1-2 \%$ year in Ahmadabad. During 2004 at Pune the highest hourly concentration was recorded to be $75 \mathrm{ppb}$. The Central Pollution Control Board (CPCB) has provided the permissible limit for ground level ozone in the year $2009,180 \mathrm{mg} / \mathrm{m}^{3}$ for one hour average and $100 \mathrm{mg} / \mathrm{m}^{3}$ for 8 -hour average value.

The literature available indicates that the studies pertaining to research on ground level ozone in India are principally focused on monitoring the concentration of ground level ozone. In the remaining studies the effects of high concentration of ozone are studied on various plant species which are important cash crops.
Thus there are limited numbers of studies which account for formation of ground level ozone in India. Another factor for consideration is that the studies which intend to understand formation of ozone consider few meteorological parameters and selected air pollutants. It is known that ozone levels pollution is deleterious to humans as well as environment, the causes for its formation is to be focused in order to plan mitigation strategies. More attention needs to be paid to the megacities of the country where the level of human exposure is greatest. Therefore the present study is an attempt to understand the trend of ground level ozone in the city of Mumbai which is one of the four megacities of India. Mumbai, the commercial capital of India with a population of about 15 million has been under constant stress due to increasing urbanization.

The city has a mean elevation of 11 meters above sea level and consists of seven islands situated on the Konkan coast, located at $18 \mathrm{o} 59^{\prime} 39 \mathrm{~N}$ latitude, $72 \mathrm{o} 48^{\prime} 55 \mathrm{E}$ longitude. It has a tropical savannah climate. The city has witnessed tremendous increase in vehicle population with the total of 11, 23,562 vehicles in the year 2003 .

The on-going air pollution measurement programs reveal that the city is experiencing substantial particulate pollution problem, with frequent and widespread excedences of total suspended particulates (TSP) and $\mathrm{PM}^{10}$ air quality standards which can be observed in the NAAMP data for the city. ${ }^{8}$ 


\section{Methodology}

The megacity of Mumbai is located on the western coast of India and experiences typical tropical climate. The city has experienced rapid growth and unplanned expansions in the past few decades. The vehicular population of the city has also been reported to grow in geometric proportion. It is estimated that daily number of vehicles are roistered the Mumbai Traffic Registration.

\section{Metrology and site description}

The meteorology, site characteristics and of the city and pollutants monitored are explained in detail by Marathe and Murthy. ${ }^{9}$

\section{Data analysis}

The hourly average data has been grouped into four seasons to study the seasonal variation.

\section{New approach}

The available literature suggests that ozone being formed by photochemical reactions takes at least one or two hours once its precursor pollutants are emitted in the atmosphere. This further depends upon the prevailing climatic conditions of the given area. The parameters selected for analysis were based on the available literature. In the present study the time taken for formation of ozone after emission of precursors is taken in to consideration. This was accomplished by offsetting the ozone values by one hour and adjusting them with the precursor pollutants. This was done before any processing or filtering of the data set of three years. In the present study the reading of ground level ozone for first hour was deleted and replaced with the reading of the proceeding hour. The readings of the last row from the data set were completely deleted in order to have uniform number of readings for statistical analysis. The gap of one hour is set by understanding that ozone formation by the photochemical reactions of precursors requires at least one hour time. In order to confirm the time delay (lag) in ozone formation regression analysis of one hour and two hours off-set values of ozone concentration was carried out separately. The results revealed that the values off-set by one hour were statistically significant than the later.

\section{Correlation}

In order to explore the relationship of ozone with other parameters correlation analysis of the parameters was conducted. The data used for analysis was converted into logarithmic form. The correlation analysis was carried out by grouping the data set diurnally. The analysis was conducted using Stats4 package in version 3.2.1 of $\mathrm{R}$ software. ${ }^{10-12}$

\section{Regression analysis}

For the purpose of regression analysis, the hourly readings of the data were converted into logarithmic form. The Step-wise regression at $90 \%$ confidence interval was carried for each season as well as entire data set together in order to highlight the parameters which are influencing ozone formation. ${ }^{13-17}$

\section{Results and discussion}

\section{Summer}

In the summer season the results reveal that the most influential parameters which supports $\mathrm{O}_{3}$ formation is temperature ' $\mathrm{t}$ ' which has an estimate loading of +1.28835 .the world most influential parameter is the one hour offset values of $\mathrm{O}_{3}$. This indicates that higher background concentrations the more amount $\mathrm{O}_{3}$ is formed.

In the initial test all the aforesaid parameters were considered for the regression. It was found that the Multiple "r-square" and adjusted "r-square" were observed to be " 0.9865 " and " 0.9864 " respectively with 5095 Degrees of freedom. It should be noted that among the selected parameters m-p-xylene was found to be insignificant even at $90 \%$ confidence interval and hence was excluded from the equation. Based on the above results the equation was re-tested for improvement. In the second test it was found that the multiple "r-square" and adjusted "r-square" remained unchanged. This indicated that the new equation is fit for to explain the ozone formation up to $98 \%$. The results indicate that all the parameters retained in the second equation are significant at $90 \%$ confidence interval. The estimate values for ' $\mathrm{H}$ ' a one hour offset values is ' +0.7896 '. It should be noted that the above parameters are purely metrological factors. Out the anthropogenic factors the most influential parameters which support $\mathrm{O}_{3}$ formation is PM10 or responsible particulate matter having the diameter of partials has then 10 micros. The pm10has an estimate loading of 0.07475 (these results indicates that the particular matter enhance formation of ground level $\mathrm{O}_{3}$. A detailed analysis of the characterization of PM10 and PM 2.5 was conducted by CPCB (2009-2010) the analysis highlighted that these particles are comprised of various matter and were subdivided as follow crustal elements, non crustal elements, organic carbons elements carbon etc. Out of this $40 \%$ of thus PM10 was made up of organic matter thus indirectly these organic molecules are contributing toward $\mathrm{O}_{3}$ formation along with other factors) (Table 1).

The most surprising finding of the research is that $\mathrm{SO}_{2}$ is the $4^{\text {th }}$ most important factor influencing $\mathrm{O}_{3}$ formation. (This parameter has not been consider in many studies because these studies have considered the par diagram discuss precursors VOCs. Therefore the reaction pathway of formation of $\mathrm{O}_{3}$ by $\mathrm{SO}_{2}$ is not well established ground level $\mathrm{O}_{3}$ and $\mathrm{SO}_{2}$ relationship. ${ }^{18}$ The next most important factor is ' $\mathrm{T}$ ' it is important to note that ' $\mathrm{t}$ ' is VOVs which is commonly observed in various application the estimate loading foe ' $t$ ' is 0.02496 .

After ' $t$ 'PM2.5 was following to be most influential in the formation $\mathrm{n}$ of the formation of $\mathrm{O}_{3}$ in summer season (but as mentioned earlier as per the CPCB 2009 study up to $40 \%$ of PM2.5 in Mumbai is made of organic matter thus indirectly organic carbons can be said to be responsible for $\mathrm{O}_{3}$ formation). The next 2 parameters responsible for $\mathrm{O}_{3}$ formation are $\mathrm{OX}$ and Benzene. They have an estimate loading of 0.00156 and 0.00123 each respectively the last parameter which have positive impact on formation $\mathrm{O}_{3}$ is $\mathrm{NOx}$ (as per traditional research is was reported that NOx is the major precursor for formation ground level $\mathrm{O}_{3}$ but a detailed analysis of various parameter along with NOx in the present study indicated that NOx in summer season has list impact on formation of $\mathrm{O}_{3}$ where as the VOCs are observed to have a greater influences on $\mathrm{O}_{3}$ formation along with $\mathrm{SO}_{2}$. This indicates that the emission of $\mathrm{SO}_{2}$ which have increase over the past few decades has lead to modification in the atmospheric chemistry for ground level $\mathrm{O}_{3}$ formation this also implies that the shift in the use of fuel; from petrol to diesel has led to modification in the pattern of $\mathrm{O}_{3}$ formation. Also another important finding of the study is that VOCs which were considered to be responsible for $\mathrm{O}_{3}$ formation or a secondary basis to have become more prominent also the study by CBCB 2009 helps to conform that the emissions of organic carbons have now taken a new form of PM10 and PM2.5 therefore effects should be made to further strengthen the studies of sources identification and quantification of organic carbon emited in the atmosphere. ${ }^{19-22}$ 


\section{Negative factors}

So far the above parameters which have been discussed were having a positive relationship which ground level $\mathrm{O}_{3}$. Now the present section focuses on the parameters which have negative relationships with ground level $\mathrm{O}_{3}$ in the summer season. The negative relationship of parameter in the summer season indicates that this molecules undergo reduction in order to contribute towards $\mathrm{O}_{3}$ formation or are responsible for scavenging the formed ground level $\mathrm{O}_{3}$ the parameter which were found to be negatively with $\mathrm{O}_{3}$ are relative humidity ,atmospheric pressure, $\mathrm{CO}, \mathrm{Eb}$. Relative humidity was found to be the most significant parameter which had and estimate loading of -0.166557 after relative humidity the atmospheric pressure expressed a negative relationship with ground level $\mathrm{O}_{3}$ the 3 factor was carbon monoxide which expressed a negative relationship with $\mathrm{O}_{3}$ the last parameter which had list impact on $\mathrm{O}_{3}$ formation was noted to be $\mathrm{EB}$ it should be noted that to be EB is an organic carbon and the only organic carbon which is found to be a negative relationship which $\mathrm{O}_{3}$. Out of the parameters considered foe the analysis it is noteworthy that MPX did not exhibit any significant impact on the process of $\mathrm{O}_{3}$ formation. The parameter which impacted positively on $\mathrm{O}_{3}$ have been compared the result of correlation analysis precisely conducted to check the indication of parameters. The comparison revels that out of a parameters which were considered for the study $\mathrm{SO}_{2}$ and NOX provided a negative correlation with ground level $\mathrm{O}_{3}$ on the parameter is positive in nature and they were found to support $\mathrm{O}_{3}$ formation also it is important to note that both the parameters expressed significant correlation of -0.6 and above. $\mathrm{SO}_{2}$ is observed to have more significant impact as compared to NOx which is evident from the estimate loading values presented in the regression analysis of the summer season. On the other hand the values for temperature and relative humidity were found to remain unchanged in both the analyses (correlation and regression). ${ }^{23-28}$ Thus it can be concluded that regression analysis using logarithmic form of the data has helped in understanding $\mathrm{O}_{3}$ formation in detail for the summer season. This study brings to light the findings that along with meteorological factors the anthropogenic factors specially the VOCs are having significant role in $\mathrm{O}_{3}$ formation along with $\mathrm{SO}_{2}$ ).

\section{Monsoon}

As we know monsoon can be considered to be the cleanest season as the pollutants occur to be low in concentration which is evident from the results for the monsoon season. The regression analysis was carried out in the similar fashion considering all the parameters mentioned in the earlier season. It was found that only eight parameters were observed to be significant having significance more than $90 \%$. The parameters which were found to be significant are presented in Table 2. It can be seen from the above table that only two parameters appear to be having negative impact on $\mathrm{O}_{3}$ formation, whereas rest of the parameters are having a positive relationship with ground level ozone. Out of the parameters which are having a positive impact on $\mathrm{O}_{3}$ formation the most significant impact is observed by temperature which having an estimate loading of ' 0.781929 '. The second most significant factor is the one hour off-set values of ozone. It can also be said that the background $\mathrm{O}_{3}$ concentrations from the earlier hour are influencing the observations conducted for ground level ozone. ${ }^{29}$

Relative humidity which was found to be having a negative relationship with $\mathrm{O}_{3}$ in summer season is observed to have a positive relationship with $\mathrm{O}_{3}$ in monsoon season. It is the third most important factor affecting $\mathrm{O}_{3}$ formation (estimate loading $=0.306073$ ). Out of the anthropogenic emissions $\mathrm{SO}_{2}$ is observed to have highest impact on $\mathrm{O}_{3}$ formation in monsoon season. The second most important factor contributing to $\mathrm{O}_{3}$ formation is $\mathrm{CO}$ having an estimate loading slightly less than that of $\mathrm{SO}_{2}$. The third and last factor positively influencing $\mathrm{O}_{3}$ formation is Benzene. Out of the parameters considered for the present study only two parameters were found to be having negative impact on $\mathrm{O}_{3}$ formation namely, atmospheric pressure and relative humidity. ${ }^{30}$

Table I Regression analysis of summer season

\begin{tabular}{llllll}
\hline Parameters & Estimate & Std. Error & $\mathbf{t}$ value & $\operatorname{Pr}(>|\mathrm{t}|)$ & \\
\hline $\mathrm{PI}$ & 0.074748 & 0.016928 & 4.416 & $\mathrm{I} .03 \mathrm{E}-05$ & $* * *$ \\
$\mathrm{P} 2$ & 0.023206 & 0.013706 & 1.693 & 0.09049 & $\cdot$ \\
$\mathrm{S}$ & 0.05577 & 0.013276 & $4.20 \mathrm{I}$ & $2.7 \mathrm{IE}-05$ & $* * *$ \\
$\mathrm{~N}$ & 0.013042 & 0.009347 & 1.395 & 0.16299 & \\
$\mathrm{C}$ & -0.065974 & 0.01242 & -5.312 & $\mathrm{I} .13 \mathrm{E}-07$ & $* * *$ \\
$\mathrm{H}$ & 0.7896 & 0.007724 & 102.233 & $<2 \mathrm{e}-16$ & $* * *$ \\
$\mathrm{~T}$ & 1.288349 & 0.079522 & 16.201 & $<2 \mathrm{e}-16$ & $* * *$ \\
$\mathrm{P}$ & -0.52229 & 0.057217 & -9.128 & $<2 \mathrm{e}-16$ & $* * *$ \\
$\mathrm{R}$ & -0.166557 & 0.03772 & -4.416 & $\mathrm{I} .03 \mathrm{E}-05$ & $* * *$ \\
$\mathrm{~B}$ & 0.012854 & 0.004672 & $2.75 \mathrm{I}$ & 0.00596 & $* *$ \\
$\mathrm{E}$ & -0.008764 & 0.006393 & -1.371 & 0.17046 & \\
Ox & 0.015555 & 0.00564 & 2.758 & 0.00584 & $* *$ \\
To & 0.024956 & 0.006191 & 4.031 & $5.64 \mathrm{E}-05$ & $* * *$ \\
\hline
\end{tabular}

Where, $\mathrm{pl}=\mathrm{PM} 10, \mathrm{p} 2=\mathrm{PM} 2.5, \mathrm{~s}=\mathrm{SO} 2, \mathrm{n}=\mathrm{NOX}, \mathrm{c}=\mathrm{CO}, \mathrm{h}=$ One hour offset values of Ozone, $t$, temperature; $p$, atmospheric pressure; r, relative humidity; b, benzene; e, ethyl benzene; ox, oxy xylene; to=toluene.

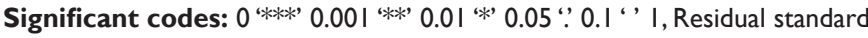
error: 0.3737 on 5096 degrees of freedom, Multiple R-squared: 0.9865 , Adjusted R-squared: 0.9864; F-statistic: $2.859 \mathrm{e}+04$ on I 3 and $5096 \mathrm{DF}$, p-value: $<2.2 \mathrm{e}-16$

Table 2 Regression analysis results for monsoon season

\begin{tabular}{llllll}
\hline Parameters & Estimate & Std. Error & t value & $\operatorname{Pr}(>|t|)$ & \\
\hline c & 0.017442 & 0.006947 & $2.51 \mathrm{I}$ & $0.012 \mathrm{I}$ & $*$ \\
$\mathrm{~s}$ & 0.019902 & 0.008779 & 2.267 & 0.0234 & $*$ \\
$\mathrm{~h}$ & 0.889004 & 0.005732 & 155.086 & $<2 \mathrm{e}-16$ & $* * *$ \\
$\mathrm{t}$ & 0.781929 & 0.11885 & 6.579 & $5.12 \mathrm{E}-\mathrm{II}$ & $* * *$ \\
to & -0.01708 & 0.002988 & -5.716 & $\mathrm{I} .14 \mathrm{E}-08$ & $* * *$ \\
$\mathrm{P}$ & -0.53195 & 0.096812 & -5.495 & $4.07 \mathrm{E}-08$ & $* * *$ \\
$\mathrm{r}$ & 0.306073 & 0.066205 & 4.623 & $3.86 \mathrm{E}-06$ & $* * *$ \\
$\mathrm{~b}$ & 0.015036 & 0.002788 & 5.393 & $7.19 \mathrm{E}-08$ & $* * *$ \\
\hline
\end{tabular}

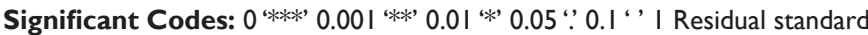
error: 0.276 on 6203 degrees of freedom, Multiple R-squared: 0.9915 , Adjusted R-squared: 0.9915 , F-statistic: $9.04 \mathrm{Ie}+04$ on 8 and 6203 DF, p-value: $<2.2 \mathrm{e}-16$.

Atmospheric pressure being more influential is followed by Toluene which is a result of anthropogenic emissions from the present analysis for monsoon season. It can be observed that most of the anthropogenic emission which contains primary pollutants namely PM10, PM2.5, NOx, etc. were observed to be minimal in concentration. This suggests that these pollutants are hydrophilic in nature and are and are degraded during the monsoon season. In a similar way it can be said that pollutants like $\mathrm{SO}_{2}, \mathrm{CO}$, BENZENE, 
and most of the VOCs have hydrophobic nature which enables these pollutants to stay in the atmosphere for longer duration and result in $\mathrm{O}_{3}$ formation. It is important to mention that NOx, PM10 and PM 2.5 when in minimal conc. Do not lead to $\mathrm{O}_{3}$ formation this can help to confirm that $\mathrm{O}_{3}$ formation is mainly dependant on the emission on pollutants and not by only environmental factors such as relative humidity, atmospheric pressure or temperature. The comparison of results of regression analysis carried out earlier revealed that only $\mathrm{SO}_{2}$, co Benzene and To are found to have significant impact on $\mathrm{O}_{3}$ formation where as a correlation analysis also indicated that $\mathrm{NO}_{\mathrm{x}}$, To and $\mathrm{Ox}$ were having a weak relationship with $\mathrm{O}_{3}$.

\section{Post monsoon season}

As discussed earlier the post monsoon season experiences the worst pollution scenario as the conc. Of ground level $\mathrm{O}_{3}$ is experienced to exceed the CPCB standard for $8 \mathrm{hr}$ and $1 \mathrm{Hr}$ on frequent basis. The stepwise logarithmic regression of all parameters in the post monsoon season experienced equal number of parameters having positive as well as negative impact on formation of $\mathrm{O}_{3}$. Out of the parameters considered for the study it was found that Amp and Benzene. Didn't have any significant impacts on $\mathrm{O}_{3}$ formation even at $90 \%$ confidence interval. The parameters which have $\mathrm{r}^{2}$ positively influencing $\mathrm{O}_{3}$ formation are temperature $\mathrm{NOx}, \mathrm{SO}_{2}, \mathrm{Ox}, \mathrm{PM} 10$ and One hour off-set values of $\mathrm{O}_{3}$. Out of these parameters one hour offset values or the concentrations of $\mathrm{O}_{3}$ in earlier hour is having highest influence on $\mathrm{O}_{3}$ readings/ values. The second most influential factor is Temperature (estimates $=0.673372$ ). The concentration of NOx was found to be positively impacting formation of $\mathrm{O}_{3}$ in the present study. Nox was to be third most influencing factor it was followed by $\mathrm{SO}_{2}$ which had marginally lesser estimate loading $(0.041554)$. The next most influential parameter is observed to be PM10 followed by Oxyxylene. (It should be noted that in the post monsoon season formation of $\mathrm{O}_{3}$ is caused due to the emissions of $\mathrm{NOx}$ and $\mathrm{SO}_{2}$. Thus is signifies that the formation is not dependant on the VOCs channel as observed in the case of summer season). Out of the parameters which are in negative relationship with $\mathrm{O}_{3}$ the most significant is relative humidity which is having as estimate loading of 0.100335 . (This implies that $\mathrm{O}_{3}$ formation is suppressed by increases in relative humidity). The most significant of all the parameters in negative relationship with $\mathrm{O}_{3}$ is pressure (estimates $=0.225945)$. (The ambient pressure is yet another meteorological factor which is observed to in negative relationship with $\mathrm{O}_{3}$. out of all the factors considered in the present study only relative humidity and pressure were found to be in negative relationship). From the anthropogenic pollutants monitored it was found that ethyl Benzene is the most influential factor having an estimate loading of ' -0.05028 '. This indicates that either undergoes reduction by photo dissociation to produce ground level $\mathrm{O}_{3}$ or it acts as a scavenger. The same can be said in the case of PM2.5, CO and Toluene which are having a negative relationship with ground level ozone. (It can be observed that all the parameters from the anthropogenic sources are carbonations in nature. Except for, the rest are organic compounds of carbon in majority including PM2.5 which has already been reported to be upto $40 \%$ made up of organic carbon. Thus it can be stated that in the post monsoon season when the concentration of relative humidity is experienced to be very low the volatile organic carbons undergo photo-dissociation inspite of being in negative relationship with ozone, they are contributing to ozone formation.

\section{Summary of season}

The post monsoon season experiences dynamic changes in climatic conditions during the day as well as night time therefore it can be concluded that the parameters irrespective of being negatively or positively related to ground level $\mathrm{O}_{3}$ In statistical fashion give rise to $\mathrm{O}_{3}$ formation this situation is aggravated by the formation of $\mathrm{O}_{3}$ which has a longer residence time in the atmosphere in this season. It can be said that the constant building up of $\mathrm{O}_{3}$ leads to formation of $\mathrm{O}_{3}$ episodes.

\section{Winter season}

The winter season is known to experiences stagnancy in atmospheric conditions. As a result a thermal inversion in vertical profile doesn't occur this leads to entrapment of pollutants at ground level leading to formation of photochemical smog. The stepwise regression analysis conducted for winter season revealed that the parameters which favor $\mathrm{O}_{3}$ formation were less in number then the once which are responsible for destruction of $\mathrm{O}_{3}$ or are in negative relation with $\mathrm{O}_{3}$. Out of the parameters which are positively influencing $\mathrm{O}_{3}$ formation the most influential parameter was observed to be one hour offset values of ground level $\mathrm{O}_{3}$. They were followed by temperature. Out of the anthropogenic pollutants which were considered for the present study it was found that $\mathrm{O}_{3}$ concentrations appeared to be enhance by the presence of PM10, SO2, Ethyl Benzene. Relative humidity and atmospheric pressure expresser a negative relationship with $\mathrm{O}_{3}$ and were found to be most influential from the factors negatively affecting $\mathrm{O}_{3}$ formation. Amongst the anthropogenic emissions it can be observed that PM2.5, CO, Benzene and M-P Xylene are the one which are negatively influencing $\mathrm{O}_{3}$ formation. Out of this PM2.5 appears to have highest influence. (The analysis reveals that in the winter season the parameters which are negatively impacting $\mathrm{O}_{3}$ formation from the anthropogenic emissions have higher percentage of organic compound. It is also important to note that for the first time in the analysis MPX has been observed to be significantly contributing in $\mathrm{O}$ formation. Similarly the contribution by NOx is observed to be statistically insignificant which helps to conclude that the contribution of NOx being negligible particularly in the winter season. A similar situation was also experience in the monsoon season during which the contribution of NOx was found to be statistically insignificant. From the above to cases it can be said that in the case of presence of moisture and high percentage of relative humidity the NOx molecules present in the atmosphere tend to behave differently. The analysis future helps to confirm the findings that the formation of $\mathrm{O}_{3}$ in winter season in experience due to $\mathrm{SO}_{2}$ primarily and due to VOcs secondly. In the case of $\mathrm{CO}$ a negative relationship can be observed as seen in the summer season. This indicates that $\mathrm{NO}_{\mathrm{x}}$ and $\mathrm{SO}_{2}$ support formation of ozone while the $\mathrm{CO}$ molecules scavenge ground level ozone and there by limit its concentration. The relationship of Toluene and Ethyl Benzene was found to be negative in the post-monsoon season while that of Oxy-Xylene was positive. There is limited literature on simultaneous long term measurements of VOCs and Ozone and hence the relationship between each VOC and ozone is unconfirmed. This study helps to bridge this gap. In the present study it can be evident that the change in season influences the behavior of precursor pollutants which are responsible for ozone formation. From the meteorological parameters considered in the study it was observed that atmospheric pressure and relative humidity exhibit a negative relationship with ground level ozone while temperature exhibits a positive relationship. ${ }^{31}$

It is important to note that the values of one hour time step exhibit a positive relationship as observed in the earlier two seasons. The positive relationship indicates that they support formation of ground level ozone. The estimate value for the parameter can be observed to highest which suggests that they have a significant role in formation 
of ozone. From the above results it can be said that the highest concentration of ground level ozone is experienced in the postmonsoon season due to the strong t-value of $\mathrm{SO}_{2}$ and $\mathrm{NO}_{\mathrm{x}}$. Another reason is that the concentration of relative humidity is very low in the season. From the results of the earlier seasons it is evident that relative humidity is scavenging ozone formed in the atmosphere. Since the percentage of relative humidity is very low in the season it contributes minimally for destruction of ozone. This is further supported by prevailing ozone concentrations which also tend to support formation of ozone by positive feed-back mechanism.

\section{Long term data of three years}

For the purpose of formulation any standard methodology it is required that the standard should be set annually. The limits cannot be changed on seasonal basis excepting few cases. Therefore separate regration analysis was conducted considering the entire data set of 3years. The analysis revealed that Benzene and TO were found to be insignificant even at $90 \%$ interval and hence were excluded from the model. The model was retested with the remaining parameters. The adjusted R2 for the equation was observed to be garter then .98 $\%$ and hence the equation was accepted. It should be noted that the most significant factor which had positive relationship with $\mathrm{O}_{3}$ the one hour off set values of ozone. The same situation is evident in all the seasons. It was seconded by temperature which is traditionally known to support $\mathrm{O}_{3}$ formation.

The concentrations of $\mathrm{SO}_{2}$ were observed to be third most significant parameter although it should be noted that influence of $\mathrm{SO}_{2}$ was observed to be highest among the anthropogenic emissions. The findings indicate that the concentration of $\mathrm{SO}_{2}$ though not alarming in nature are contributing in $\mathrm{O}_{3}$ formation. The study thus can help in paradigm shift from NOx and VOC limited $\mathrm{O}_{3}$ formation to $\mathrm{SO}_{2}$ limited $\mathrm{O}_{3}$ formation. After the $\mathrm{SO}_{2}, \mathrm{NOx}$ values were observed to have a significant impact on $\mathrm{O}_{3}$ formation. This kind situation was not observed in seasonal analysis. In most of the seasons NOx was observed to be minimally significant. The values of PM10 were observed to impact $\mathrm{O}_{3}$ formation in positive fashion ahead of ozxyxyllene and benzene. It interesting to note that in the seasonal analysis VOCs and PM10 were observed to have greater influence on $\mathrm{O}_{3}$ formation as compared to NOx. But when the equations are tested for entire data sets the results appears to be exactly opposite. Oxyxylene and benzene exhibit a weak positive influence as compared to PM10. The difference between the estimates of PM10 and NOx is marginal which helps to confirm that VOCs play a major role in $\mathrm{O}_{3}$ formation. As observed in earlier cases of seasonal analysis the atmospheric pressure and relative humidity continue to be negatively related with $\mathrm{O}_{3}$.

It is important to note that located on the coastal belt and hence the variation in atmospheric pressure is minimal. Even though it is observed that the minute changes in pressure are affecting formation of $\mathrm{O}_{3}$. Some studies have reported that relative humidity is inversely proportional to $\mathrm{O}_{3}$ (REF.) the same findings can be conformed for the case of Mumbai city. Since relative humidity is negatively related with $\mathrm{O}_{3}$ it can be termed as a scavenger of $\mathrm{O}_{3}$. Therefore the concentration of $\mathrm{O}_{3}$ can be observed to be highest in post monsoon season during which relative humidity is experience to be minimal. Hence the observations of $\mathrm{O}_{3}$ for Mumbai city can be said to have a unique nature. Amongst the anthropogenic pollutants Co was found to be most influential in distraction of $\mathrm{O}_{3}$ as it was found to be inversely related to $\mathrm{O}_{3}$. This relationship has also been reported in other studies (REF.)
The values of PM2.5 were observed to be negatively related with $\mathrm{O}_{3}$ followed by MPX. Out of the two MPX was observed to have minimal influence. One of the most important finding of the present study is that all the major meteorological factors considered in the study are having statically significant contribution in either formation or destruction of $\mathrm{O}_{3}$. But it should be noted that out of anthropogenic emissions the concentrations of $\mathrm{SO}_{2}$ was found to be significantly contributing to $\mathrm{O}_{3}$ formation even at lower concentrations in comparison with NOx. Nox which was traditionally considered to be the most important pollutant favoring $\mathrm{O}_{3}$ formation was noticed to be significant only in two seasons especially when the low percentage of humidity was experienced. Thus it can be said that as humidity increases it interferes with the formation of $\mathrm{O}_{3}$ by NOx channel. Royal Society (2008) reports that $\mathrm{OH}$ radicals help in reduction of NOx. Apart from $\mathrm{SO} 2$ and $\mathrm{NOX}$ which favour $\mathrm{O}_{3}$ formation $\mathrm{CO}$ was observed to be in negative relationship with $\mathrm{O}_{3}$. $\mathrm{CO}$ is also known to be a $\mathrm{CFC}$ it was observed that $\mathrm{CO}$ supports $\mathrm{O}_{3}$ formation. When relative humidity is around $99 \%$ in rest of the cases $\mathrm{CO}$ acts as a scavenger of $\mathrm{O}_{3}$. The same understanding can be said to be applicable to PM2.5 which exhibits similar relationship with $\mathrm{O}_{3}$. Except in the monsoon season when $\mathrm{Rh}$ is around 99\%, the particles of size PM2.5 continue to scavenge $\mathrm{O}_{3}$ from the atmosphere. According to the study by CPCB (2009) $40 \%$ of the PM2.5 though being comprised of organic compounds, these exhibit a relationship exactly opposite to that of PM10. Both the particles were found to contribute significantly in three seasons except monsoon. It is also important to note that the study by CPCB (2009) involved source apportionment of PM10 and PM2.5, concluded that the sources for PM10 and that for PM2.5. That can be said to be a major factor. Another pollutant which was observed to be significant in 3 seasons is benzene a Voc. It was observed to be insignificant in the post monsoon season. It can be said that benzene tends to photo-dissociate at high temperature in absence of relative humidity. On the contrary, Oxy-xylene tends to favour $\mathrm{O}_{3}$ formation in low humidity as well as high humidity scenarios. Ethyl benzene being significantly influencing $\mathrm{O}_{3}$ formation is not observed in the consolidated analysis. This can be said to be because of the fluctuating relationship in seasonal analysis.

\section{Acknowledgments}

None.

\section{Conflicts of interest}

The authors declare there is no conflict of interests

\section{Funding}

None.

\section{References}

1. Akdemir Andac Ozel Ummukulsum, Nuri Ergun Osman. Multivariate regression analysis for ground-level ozone modeling in Kurupelit, Samsun, Turkey, 2013;22(86):84-89.

2. EEA Technical report. Air pollution by ozone across Europe during summer 2008. Europe: European Environment Agency; 2009.

3. Agrawal M. Experimental evidence of $\mathrm{O}_{3}$ impacts on crop yield and quality in India. Presented at a Royal Society workshop on groundlevel; 200.

4. Denman KL. Couplings between changes in the climate system and biogeochemistry. In: Solomon SD, Qin D, Manning M, editors. Climate Change 2007:The Physical Science Basis. Contribution of Working Group I to the Fourth Assessment Report of the Intergovernmental Panel on Climate Change. Cambridge, UK: Cambridge University Press; 2007. 
5. Lelieveld J, Van Aardenne J, Fischer H, et al. Increasing ozone over the Atlantic Ocean. Science. 2004;304:1483-1487.

6. Atkinson R. Atmospheric chemistry of VOC and NOX. Atmospheric Environment. 2000;34:2063-2101.

7. W Williamson. Bemerkungen and Versuche über die Ozontheorie Analytical chemistry pharmacy 61, 13-37.[(cited as a cross reference in Mordecai B Rubin (2001) The History of ozone. Schönbein period (18929-1868):Bulletin for the History of Chemistry 26(1)]. 1847.

8. Chand D, Lal S. High ozone at rural sites in India. Atmos Chem Phys Discuss. 2004;4:3359-3380.

9. Marathe S, Murthy S. Seasonal Variation in Surface Ozone Concentrations, Meteorology and Primary Pollutants in Coastal Mega City of Mumbai, India. Journal of Climatology and Weather Forecasting. 2015;3(3):149.

10. Chang L, Miller FJ, Ultman J, et al. Alveolar epithelial cell injuries by sub-chronic exposure to low concentrations of ozone correlate with cumulative exposure. Toxicology and Applied Pharmacology. 1991;109:219-234.

11. Christopher G Reuther. Winds of Change reducing trans boundary air pollutants. Environ Health Perspect. 2000;108:4

12. Crutzen PJ. Photochemical reactions initiated by and influencing $\mathrm{O} 3$ in the unpolluted troposphere. Tellus. 1974;26(1-2):47-57.

13. EEA. Air Pollution in Europe 1990-2004. EEA Report No2/2007. European Environment Agency: Copenhagen, Europe; 2007.

14. Fehsenfeld. Overview of the 2004 summer field study; Journal of Geophysical Research, 111. International Consortium for Atmospheric Research on Transport and Transformation (ICARTT):North America to Europe; 2006

15. Gettelman A, Holton JR, Rosenlof KH. Mass fluxes of O3, CH4, N2O, and $\mathrm{CF} 2 \mathrm{Cl} 2$ in the lower stratosphere calculated from observational data. Journal of Geophysical Research. 1997;102, D15:19149-19159.

16. Institute of Physics. The Rise of Ozone Research. 2005.

17. Khemani. Study of surface ozone behavior at urban and forested sites in India. Atmospheric Environment. 1995;29(16):2021-2024.

18. Mudway, Kelly. An investigation of inhaled ozone dose and the magnitude of airway inflammation in healthy adults. American Journal of Respiratory and Critical Care Medicine. 2004;169(10):1089-1095.
19. Olivier. Recent trends in global greenhouse gas emissions:regional trends and spatial distribution of key sources. In: coord Van Amstel A editor. Non- $\mathrm{CO}_{2}$, Greenhouse Gases (NCGG-4). 2005:325-330.

20. Olsen MA, Schoeberl MR, Douglass AR. Stratosphere- troposphere exchange of mass and ozone. Journal of Geophysical Research. 2004;109(D24).

21. Parliamentary office of science and Technology UK. Air quality in the $\mathrm{UK} ; 2002$.

22. Prather M, Michael Gauss, Terje Berntsen, et al. 'Fresh air in the 21 st century?' Geophysical Research Letters. 2003;30(2):1100.

23. Roy S, Beig G, Ghude S. Exposure-plant response of ambient ozone over the tropical Indian region. Atmos Chem Phys Discuss. 2009;(9):41414157.

24. Singh E, Tiwari S, Agrawala M. Variability in antioxidant and metabolite levels, growth and yield of two soybean varieties:An assessment of anticipated yield losses under projected elevation of ozone. Agriculture, Ecosystems and Environment. 2009;135(2010):168-177.

25. Suqin Han, Hai Bian, Yinchang Feng, et al. Analysis of the Relationship between $\mathrm{O}_{3}, \mathrm{NO}$ and $\mathrm{NO}_{2}$ in Tianjin, China, Aerosol and Air Quality Research. 2011;11:128-139.

26. Tuomas Lauril, Juha-Pekka Tuovinen, Virpe Tarvainen, et al. Trends and scenarios of ground level ozone concentrations in Finland. Boreal Environment Researc. 2004;9:167-186.

27. USEPA. Air quality criteria for ozone and related photochemical oxidants EPA 600/R-05/004a. 2006.

28. Vingarzan R. A review of surface ozone background levels and trends. Atmospheric Environment. 2004;38(21):3431-3442.

29. Wu H, L Chan. 'Surface ozone trends in Hong Kong in 1985-1995'. Environment International. 2001;26(4):213-222.

30. WHO. Handbook of ground level ozone pollution prevention and abatement handbook World Bank group effective. 1998

31. WHO. Air quality guidelines: global update 2005, particulate matter, ozone, nitrogen dioxide and sulphur-dioxide. WHO Regional Office for Europe: Copenhagen, Europe; 2006. 